\title{
Neurophysiological differences in reward processing in anhedonics
}

\author{
Gonçalo Padrão • Aida Mallorquí • David Cucurell • \\ Josep Marco-Pallares • Antoni Rodriguez-Fornells
}

Published online: 12 September 2012

(C) Psychonomic Society, Inc. 2012

\begin{abstract}
Anhedonia is characterized by a reduced capacity to experience pleasure in response to rewarding stimuli and has been considered a possible candidate endophenotype in depression and schizophrenia. However, it is still not well understood whether these reward deficits are confined to anticipatory and/or to consummatory experiences of pleasure. In the present study, we recorded electrophysiological responses (event-related brain potentials [ERPs] and oscillatory activity) to monetary gains and losses in extreme groups of anhedonic and nonanhedonic participants. The anhedonic participants showed reduced motivation to incur risky decisions, especially after monetary rewards. These sequential behavioral effects were correlated with an increased sensitivity to punishment, which psychometrically characterized the anhedonic group. In contrast, both
\end{abstract}

G. Padrão · A. Mallorquí • D. Cucurell · J. Marco-Pallares ·

A. Rodriguez-Fornells

Cognition and Brain Plasticity Group, Bellvitge Biomedical

Research Institute (IDIBELL), L'Hospitalet de Llobregat,

Barcelona, Spain

G. Padrão $•$ D. Cucurell $•$ J. Marco-Pallares •

A. Rodriguez-Fornells

Department of Basic Psychology, University of Barcelona,

L'Hospitalet de Llobregat,

Barcelona, Spain

A. Mallorquí

Institut d'Assistència Sanitària de Girona (IAS),Salt,

Parc Hospitalari Martí i Julià,

Girona, Spain

A. Rodriguez-Fornells

Institució Catalana de Recerca i Estudis Avançats (ICREA),

Barcelona, Spain

\section{A. Rodriguez-Fornells $(\bowtie)$}

Deparment de Psicologia Bàsica,Faculty of Psychology,

Campus Bellvitge, L'Hospitalet de Llobregat,

Feixa Llarga 08907, Spain

e-mail: arfornells@gmail.com electrophysiological measures associated with the impacts of monetary losses and gains - the feedback-related negativity (FRN) and the beta-gamma oscillatory componentclearly revealed preserved consummatory responses in anhedonic participants. However, anhedonics showed a drastic increase in frontal medial theta power after receiving the maximum monetary gain. This increase in theta oscillatory activity could be associated with an increase in conflict and cognitive control for unexpected large positive rewards, thus indexing the violation of default negative expectations built up across the task in anhedonic participants. Thus, the present results showed that participants with elevated scores on Chapman's Physical Anhedonia Scale were more sensitive to possible punishments, showed deficits in the correct integration of response outcomes in their actions, and evidenced deficits in sustaining positive expectations of future rewards. This overall pattern suggests an effect of anhedonia in the motivational aspects of approach behavior rather than in consummatory processes.

Keywords Anhedonia $\cdot$ Reward processing $\cdot$ Feedbackrelated Negativity $\cdot$ Medial-frontal theta oscillatory activity . Beta-gamma oscillatory activity $\cdot$ Motivation

Recent years have shown a renewed interest in the study of affective processes, and particularly in the psychological and neural mechanisms that explain the interaction between goal-directed behavior, reward, and motivation. One of the most important aspects that has been somehow neglected, yet is crucial to understanding motivated behavior, is individual differences in anhedonia. The concept of "anhedonia" refers to a reduction of the ability to experience pleasure (Meehl, 1975), as reflected in a diminished interest in rewarding stimuli and pleasurable events. Anhedonia has been described as a prominent symptom and potential trait marker of major depression (Loas, 1996) and is broadly studied in relation to schizophrenia and the negative- 
symptoms spectrum (Foussias \& Remington, 2008). While the importance of this concept is well established in psychopathology (Berrios \& Olivares, 1995), the neurophysiological mechanisms associated with it are still ambiguous. A possible dysfunction in the reward and motivation systems has been lately proposed to explain the link between anhedonia and depression (Keedwell, Andrew, Williams, Brammer, \& Phillips, 2005; Naranjo, Tremblay, \& Busto, 2001; Nestler \& Carlezon, 2006; Pizzagalli et al., 2009; Treadway \& Zald, 2011).

Anhedonia as a trait has also been characterized in clinical and nonclinical populations, showing stable individual differences across time (Blanchard, Horan, \& Brown, 2001; Herbener, Harrow, \& Hill, 2005; Shankman, Nelson, Harrow, \& Faull, 2010). Considering its clinical importance and substantial heritability (Bogdan \& Pizzagalli, 2009), the anhedonia trait has been proposed as a very promising endophenotype for depression (Hasler, Drevets, Manji, \& Charney, 2004) and has been used already to disentangle reward abnormalities observed in depression (Harvey, Pruessner, Czechowska, \& Lepage, 2007; Pizzagalli, Jahn, $\&$ O'Shea, 2005) and schizophrenia (Harvey, Armony, Malla, \& Lepage, 2010; Herbener \& Harrow, 2002). Endophenotypes represent subclinical traits associated with vulnerability to expressing a mental disorder, are heritable and state-independent, and can manifest in individuals whether or not illness is active (Gottesman \& Gould, 2003). The study of subclinical samples is very important, especially to rule out the effects of confounding factors inherent to clinical states.

Although anhedonia usually refers to a reduction in the capacity to experience pleasure from rewarding events, anhedonics usually show diminished motivation to engage in goal-directed behaviors and to use information about potentially rewarding events during decision-making. Therefore, an important challenge in the study of anhedonia is to clarify whether anhedonia is a reflection of a singular hedonic deficit per se, or an alteration in motivational approach behavior. This distinction is critical to better understand individual differences regarding hedonic experiences in clinical populations. Previous studies in clinical samples of schizophrenia have suggested that while the experience to engage in enjoyable activities seems to be more or less preserved (Gard, Kring, Gard, Horan, \& Green, 2007; Kring \& Moran, 2008), these patients report less anticipatory pleasure in goal-directed activities that could potentially allow them to obtain desired rewarding experiences (Barch \& Dowd, 2010). Moreover, two recent clinical studies of anhedonia and depression in a college student population primarily reflected low levels of anticipation of reward and a tendency to accurately estimate their enjoyment of future rewards (Chentsova-Dutton \& Hanley, 2010; Sherdell, Waugh, \& Gotlib, 2012). These findings give support to the idea that anhedonia in clinical settings might be a consequence of deficits in motivation and anticipatory, but not necessarily consummatory, pleasure.

The dissociation between consummatory and anticipatory processes suggests a specific deficit in keeping internal representations of possible rewarding experiences active, and therefore reducing the possibilities to correctly direct actions. Indeed, this notion is consistent with a recent neuroimaging study (Heller et al., 2009) showing that depression may not be solely due to a tonic reduction in the capacity to experience pleasure, but to the inability to sustain positive affect and reward responsiveness over time. Convergently, a growing body of literature has put forward different neural networks and neurotransmitters involved in consummatory and anticipatory pleasure in goal-directed motivation (Berridge, 2004; Berridge \& Kringelbach, 2008; Berridge \& Robinson, 1998; Salamone, Correa, Farrar, \& Mingote, 2007). Most importantly, as dopamine has been proposed to be involved in both anticipatory and consummatory processes, the current view favors the crucial role of this neurotransmitter in guiding reward prediction processes (Berridge, 2004). Indeed, recent research has shown that depletion of dopamine does not affect consummatory reactions, whereas the opioid and the gamma-aminobutyric acidergic systems in the ventral striatum are important in regulating the experiences of pleasure (Barbano \& Cador, 2007; Burgdorf \& Pankseep, 2006; Richardson, Reynolds, Cooper, \& Berridge, 2005; Smith \& Berridge, 2007).

The present study seeks to clarify whether the dissociation observed between reward consumption and the changes observed in motivational approach behavior could help us understand the origin of the individual differences observed in anhedonia in subclinical populations. In the present investigation, we recorded for the first time event-related brain potentials (ERPs) in two very extreme groups of anhedonic $(\mathrm{ANH}+)$ and nonanhedonic $(\mathrm{ANH}-)$ healthy participants while performing a monetary gambling task, in which gains and losses were randomly administered. Anhedonia was measured using the Physical Anhedonia Scale (PAS) (Chapman, Chapman, \& Raulin, 1976). By using the gambling task, we aimed at two crucial goals: (1) the exploration of consummatory pleasure responses to monetary gains and losses in individuals with trait anhedonia by means of electrophysiological measures, and (2) the observation of differences in anticipatory pleasure by considering the risk patterns of anhedonic and nonanhedonic individuals and evaluating dynamic trial-by-trial adjustments in risk choices according to the history of gains and losses.

With the first goal in mind, we explored high-frequency beta-gamma oscillations $(20-35 \mathrm{~Hz})$ to measure consummatory reactions to positive outcomes (monetary gains) in both groups of participants. In humans, increases in cortical electroencephalogram (EEG) beta oscillations have been 
reported during consumption of sensory rewards (Hallschmid, Molle, Fisher, \& Born, 2002). Also, increase in beta-gamma EEG power has been recently associated with the processing of positive feedback related to monetary gains (Cohen, Elger, \& Ranganath, 2007; Haji Hosseini, Rodríguez-Fornells, \& Marco-Pallarés, 2012; Marco-Pallarés et al., 2008; MarcoPallarés et al., 2009). These studies together suggest that beta-gamma activity is a potential brain signature of reward processing.

In addition, we decided to study the feedback-related negativity (FRN) and medial-frontal theta oscillatory activity to evaluate consummatory reactions to negative outcomes (monetary losses). The FRN is a midfrontal component of ERPs, usually elicited by performance feedback such as incorrect responses/errors or negative outcomes - for instance, monetary losses (Gehring \& Willoughby, 2002; Holroyd \& Coles, 2002). Moreover, the FRN has been consistently associated with medial-frontal theta oscillatory activity $(4-7 \mathrm{~Hz})$ (Cavanagh, Frank, Klein, \& Allen, 2010; Cohen et al., 2007; Marco-Pallarés et al., 2008; Trujillo \& Allen, 2007). Thus, the FRN is thought to reflect the degree of negative prediction error, a signature when events are worse than expected, due to decreased mesencephalic dopaminergic activity that is transmitted to the medial prefrontal cortex (mPFC) (Holroyd \& Coles, 2002; Nieuwenhuis, Holroyd, Mol, \& Coles, 2004). Accordingly, these signals in the mPFC might help the organism to detect potential cognitive conflicts arising from previous expectations and unexpected outcomes, enhancing action monitoring and control processes (Botvinick, Cohen, \& Carter, 2004; Holroyd \& Coles, 2002; Ridderinkhof, Ullsperger, Crone, \& Nieuwenhuis, 2004). In this regard, it has been proposed that increases of the medial-frontal theta component may represent a general top-down mechanism operating over expectation violation and behavioral adaptation in order to improve performance and learning (Cavanagh et al., 2010; Cunillera et al., 2012; Tzur \& Berger, 2009; van de Vijver, Ridderinkhof, \& Cohen, 2011; Womelsdorf, Johnston, Vinck, \& Everling, 2010).

In sum, using both beta-gamma and FRN/medial-frontal theta oscillatory signals, we investigated the degrees of activation of the reward system in $\mathrm{ANH}+$ and $\mathrm{ANH}-$ participants. On the basis of previous findings in anhedonic populations in which no differences were observed regarding the expression of emotion when exposed to emotional stimuli (Berenbaum, Snowhite, \& Oltmanns, 1987; Berlin, Givry-Steiner, Lecrubier, \& Puech, 1998; Germans \& Kring, 2000; but, for discrepant results, see Fitzgibbons \& Simons, 1992; Rey et al., 2010), we predicted that no differences between groups would be observed in reaction to positive (monetary gains) and negative (monetary losses) feedback EEG components (respectively, the beta-gamma and FRN/medial-frontal theta components), supporting the proposal of intact consummatory pleasure in anhedonics.
In relation to the second objective, changes in motivational approach behavior between groups were investigated, focusing the analysis on the risk patterns observed after monetary gains and losses. Previous studies have shown that participants tend to increase their risk-seeking behavior after losing large amounts of money (Gehring \& Willoughby, 2002) or when monetary losses are very salient (Kahneman \& Tversky, 1979). These studies have highlighted the importance of studying dynamic adjustments of cognitive control processes that allow for a more flexible adjustment of performance in response to changing environmental demands and changing internal goal states (Carter and van Veen 2007). On the basis of previous findings (Steele, Kumar, \& Ebmeier, 2007), we predicted a larger impact of the trait of anhedonia on the capacity to anticipate rewarding experiences, and therefore on the risk patterns observed during the gambling task. This prediction was based on previous studies showing that depressed patients who tended to focus on negative rather than positive aspects of their lives (Beck, 1979; Lloyd \& Lishman, 1975; Nelson \& Craighead, 1977) had experienced less positive reinforcement within their life (Lewinsohn, Youngren, \& Grosscup, 1979), therefore predicting increased attention in risk situations (that could potentially result in a punishment) and less expectation of receiving positive feedback. Finally, we simultaneously assessed using two psychometric questionnaires the differences between our groups in their susceptibility to avoiding possible negative events (punishments) or in their tendencies to seek positive experiences or rewards (Carver \& White, 1994; Torrubia, Ávila, Molto, \& Caseras, 2001).

\section{Materials and methods}

\section{Participants}

A group of 43 healthy undergraduate students of the University of Barcelona participated in the experiment (7 male, 36 female; mean age $=22 \pm 2.3$ years) in return for monetary compensation. The amount of the monetary bonus depended, in part, on the participants' performance. All of the participants gave written informed consent, and the study was approved by the local ethics committee. None of the participants reported a history of neuropsychiatric disorders.

\section{Psychometric assessment}

The 61-item Physical Anhedonia Scale (PAS; Chapman et al., 1976) was used to assess the distribution of the anhedonia trait in a healthy Spanish population of 650 university students. In order to select the sample for the present study, extreme high and low anhedonic groups were selected. By using the mean of the distribution as a center $(M=13.5, S D=7)$ and applying 
$1.5 S D$ s, we evaluated two statistically different groups: the anhedonia-trait group (hereafter, $\mathrm{ANH}+$ ), represented by participants having PAS scores over 24 (21 participants), and the nonanhedonia-trait group (ANH-), composed of participants with scores lower than 5 (22 participants). The mean PAS scores for both groups in the present sample were $\mathrm{ANH}+, 26.9$ \pm 3.2 , and $\mathrm{ANH}-, 3.4 \pm 1.2$.

All participants were also screened with questionnaires designed to assess personality measures related to aversive and approach motivation and responsiveness to rewards and punishments. We selected the BIS/BAS scales (Carver \& White, 1994) and the Sensitivity to Punishment and Sensitivity to Reward Questionnaire (SPSRQ; Torrubia et al., 2001). The BIS/BAS scales are self-report measures intended to assess individual differences in temperament related to two physiological self-regulatory systems, originally formulated by Gray (1981). On the one hand, the behavioral inhibition system (BIS) is thought to be more sensitive to cues that anticipate punishment and trigger inhibition and negative affect toward potentially stressful events. On the other hand, the behavioral approach system (BAS) is reflected in proneness to engage in goal-directed efforts and positive affect when the person is exposed to cues of impending reward. While the BIS scale is unidimensional, there are three BAS subscales. Items from the BAS Drive subscale evaluate persistence in chasing desired goals, the Fun Seeking (FS) subscale has items reflecting desire and willingness to approach a potentially rewarding event, and the Reward Responsiveness (RR) subscale has items that focus on positive responses to the occurrence or anticipation of rewarding events. The SPSRQ is composed of two scales, the Sensitivity to Punishment scale (SP) and the Sensitivity to Reward scale (SR). The SP items reflect behavioral responses to cues of punishment, to situations involving novelty, or to the possibility of aversive consequences, as well as cognitive processes produced by the threat of failure in goals. SR items describe situations in which people employ efforts to obtain rewarding experiences (e.g., money, sex partners, or social events). Both scales are intended to assess both neural systems-BIS and BAS functioning (Gray, 1981) — and have shown clear functional and structural correlates in recent neuroimaging studies (Camara, Rodriguez-Fornells, \& Münte, 2010).

\section{Procedure}

The gambling task consisted of choosing one of two numbers presented in white on a black background in the middle of a video screen (Camara, Krämer, et al., 2010; Marco-Pallares et al., 2008). Only two possible displays were presented, either [25 5] or [5 25] (for an example of a trial, see Fig. 1). Participants had to make an obligatory buttonpress response with their left or right index finger, indicating the number selected. For example, in the [25 5] display, a left buttonpress would indicate selection of the number 25 , and a right buttonpress selection of the number 5 . After the response choice (with a fixed interval of $800 \mathrm{~ms}$ ), one of the numbers would turn red while the other turned green. If the number selected by the participant changed to red, this signaled a loss of the corresponding amount in Euro cents; a green number indicated a gain of this amount in Euro cents. The duration of the feedback stimulus was $1,000 \mathrm{~ms}$. The next trial began with the presentation of a warning signal ("+,", with a 400-ms duration), followed by a new pair of numbers.

The experiment consisted of 17 blocks of 40 trials. In each block, the four different feedback types were presented

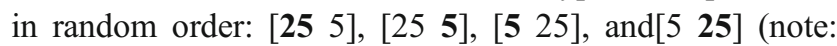
nonbold font stands for red [a loss], while bold font for green [a win]). Participants were encouraged to gain as much as possible. Combined with the two response options, this yielded eight different types of stimulus-response combinations. For example, if the volunteer had chosen the left number in a [25 5] event, this was scored as a "maximumgain" trial. If the participant had opted for the right number, however, the trial was scored as a minimum loss. For the analysis presented here, left and right choices were combined into four different averages: maximum gain $(+25)$, minimum gain $(+5)$, minimum loss $(-5)$, and maximum loss $(-25)$.

Importantly, the mean expected value of the monetary outcome was zero on each block, so as to avoid potential confounding influences of a differential probability of gains or losses. The participants were informed about their accumulated amount of money (10-s duration) after miniblocks of ten trials.

\section{Electrophysiological recording}

EEGs were recorded using tin electrodes mounted in an elastic cap and located at 29 standard positions (Fp1/2, Fz, F7/8, F3/ 4, Fc1/2, Fc5/6, Cz, C3/4, T7/8, Cp1/2, Cp5/6, Pz, P3/4, P7/ $\mathrm{P} 8, \mathrm{Po} 1 / 2$, and $\mathrm{O} 1 / 2$ ). Biosignals were referenced offline to the mean of the activity at the two mastoid processes. Vertical eye movements were monitored with an electrode at the infraorbital ridge of the right eye. Electrode impedances were kept below $5 \mathrm{k} \Omega$. The electrophysiological signals were filtered with a bandpass of $0.01-70 \mathrm{~Hz}$ (half-amplitude cutoffs) and digitized at a rate of $250 \mathrm{~Hz}$. Trials with amplitudes of more or less than $100 \mu \mathrm{V}$ were rejected offline.

\section{Data analysis}

Event-related potentials time-locked to the color change of the number-displays were averaged for epochs of $700 \mathrm{~ms}$, starting $100 \mathrm{~ms}$ prior to the stimulus (baseline). The possible differences were tested using repeated measures analyses of 


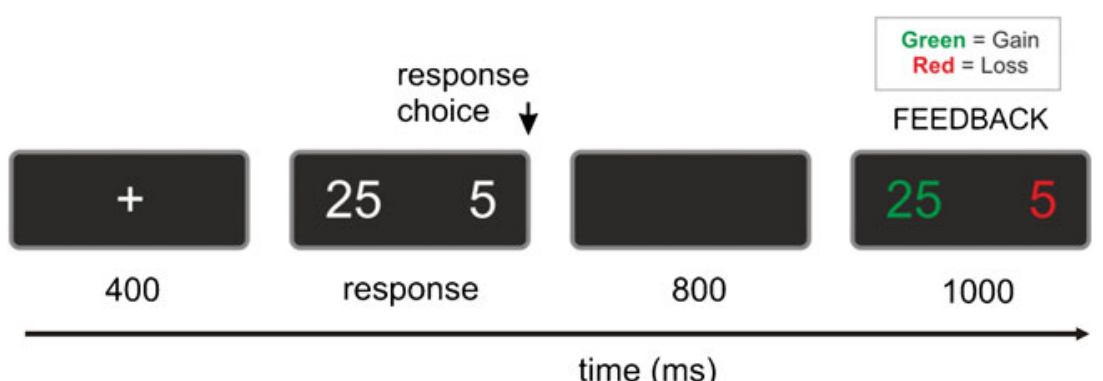

Fig. 1 Sequence of stimulus and response events in the gambling task used in the present study (Marco-Pallarés et al., 2008). After a warning signal, a pair of numbers ([5 25] or [25 5]) was presented, and participants were forced to select one of the two alternatives by pressing the corresponding button on the left- or right-hand side (response

variance (ANOVAs) with the factors Valence (gain and loss), Magnitude (maximum [25] and minimum [5]), and Midline Electrode Locations (frontal, Fz; central, Cz; and parietal, $\mathrm{Pz}$ ) analyzed within subjects and between groups $(\mathrm{ANH}+$ and $\mathrm{ANH}-)$.

To study the time-frequency behavior of the electrical activity elicited by the feedback, 4,000-ms epochs were generated (2,000 ms before and after stimulus), and singletrial data were convoluted with a seven-cycle complex Morlet wavelet (Marco-Pallarés et al., 2008). Changes in timevarying energy (square of the convolution between the wavelet and signal) in the studied frequencies (from 1 to $40 \mathrm{~Hz}$, linear increase) with respect to baseline were computed for each trial and averaged for each participant before performing a grand average. The data were analyzed in a repeated measures ANOVA with the within-subjects and between-group ( $\mathrm{ANH}+, \mathrm{ANH}-$ ) factors Valence (gain, loss), Magnitude (maximum, minimum), and Electrode Location $(\mathrm{Fz}, \mathrm{Cz}, \mathrm{Pz})$. For the decomposition of the significant interactive effects between the main factors (Valence, Magnitude, and Electrode) and Group, we used pairwise two-tailed $t$ tests for independent sample comparisons $(\mathrm{ANH}+\mathrm{vs}$. ANH- group; $p<.05$ ).

\section{Results}

Psychometric results

To assess differences between groups related to aversive and approach motivation and responsiveness to rewards and punishments, we used independent two-tailed $t$ tests (see Fig. 2). The comparisons suggested an increased sensitivity to punishment in the $\mathrm{ANH}+$ as compared with the $\mathrm{ANH}-$ group, reflected by higher scores in the BIS [means: ANH+, $24.1 \pm 3.8 ; \mathrm{ANH}-, 21.45 \pm 3.8 ; t(41)=2.1, p<.05]$ and $\mathrm{SP}$ $[\mathrm{ANH}+, 14.2 \pm 6.4$; ANH-, $8.6 \pm 5.4 ; t(41)=3.1, p<.003]$ scales. In addition, $\mathrm{ANH}+$ was less sensitive to rewarding choice). One second after the response choice, one of the numbers turned red and the other green (feedback) indicating a gain (green) or loss (red) of the corresponding amount of money, in Euro cents

events than was ANH- [SR scores: $\mathrm{ANH}+, 8.4 \pm 4.3$; ANH-, $11.5 \pm 3.9 ; t(41)=-2.5, p<.05]$.

The measures that evaluate appetitive motivation (BAS) suggested reduced tendencies of the $\mathrm{ANH}+$ group to (1) persist in actions that could potentially yield desired outcomes [BAS Drive: $\mathrm{ANH}+, 11.2 \pm 1.8$; ANH-, $12.5 \pm 1.9 ; t(41)=-2.1, p<.05] ;$ (2) approach rewarding cues [Fun Seeking (FS): $(\mathrm{ANH}+, 10.7 \pm 2.5$; ANH-, $12.3 \pm 2.4 ; t(41)=-2.2, p<.05] ;$ and (3) develop positive affect in the anticipation of rewarding cues [Reward Responsiveness (RR): $\mathrm{ANH}+, 14.8 \pm 2.6$; $\mathrm{ANH}-$, $16.2 \pm 2.5 ; t(41)=-1.9, p<.06]$ (see Fig. 2).

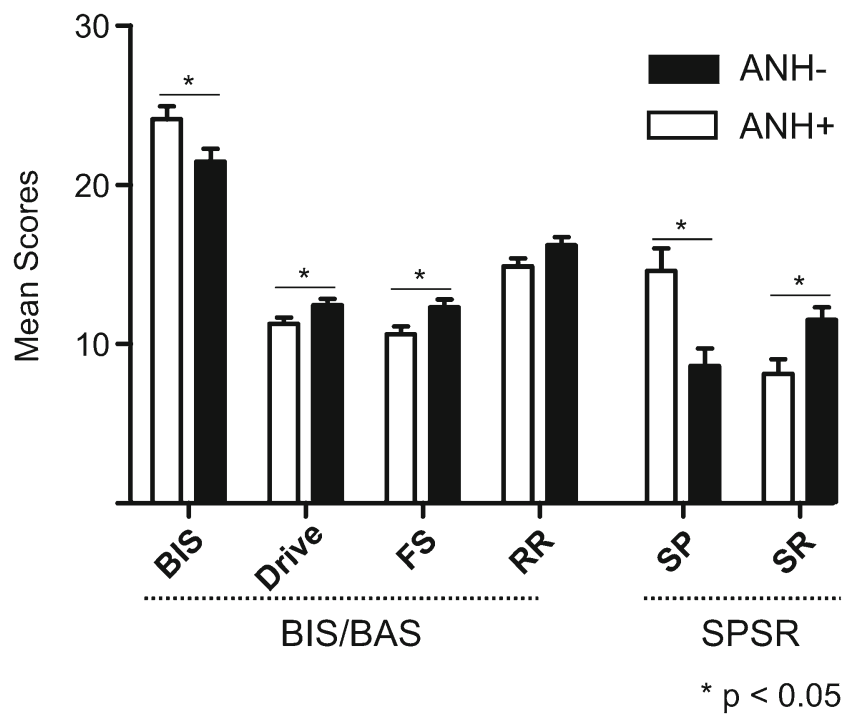

Fig. 2 Summary of psychometric results: Mean scores for both groups (and results of the between-group $t$ test comparison) regarding the BIS and BAS subscales (Drive, Fun Seeking [FS], and Reward Responsiveness [RR]), and the SPSRQ subscales (Sensitivity to Punishment [SP] and Sensitivity to Reward [SR]). Error bars represent standard errors of the means 
Behavioral analysis of risk

No differences were observed in the amounts of money collected by each group during the gambling task $[\mathrm{ANH}+$, $\sim € 0.10 ; \mathrm{ANH}-\sim € 0.30 ; t(41)<1]$. In order to explore the evolution of risk behavior across the whole ERP task, we grouped all trials in 17 bins of 40 trials each. The ANHgroup showed a constant tendency to undertake risky bets. For exploring this pattern, we performed serial one-sample $t$ tests in which the $25 / 5$ proportions of risky decisions were compared to the expected chance level (.50). As can been seen in Fig. 3a, the ANH- group was significantly above chance level $(p<.05)$ from Bins 1 to 9 , and again at Bin 15. In contrast, the $\mathrm{ANH}+$ group showed only two bins above chance level (Fig. 3a). To directly compare both groups, we carried out an ANOVA on the proportions of risk decisions (i.e., selecting 25 rather than 5) for the 17 bins and both
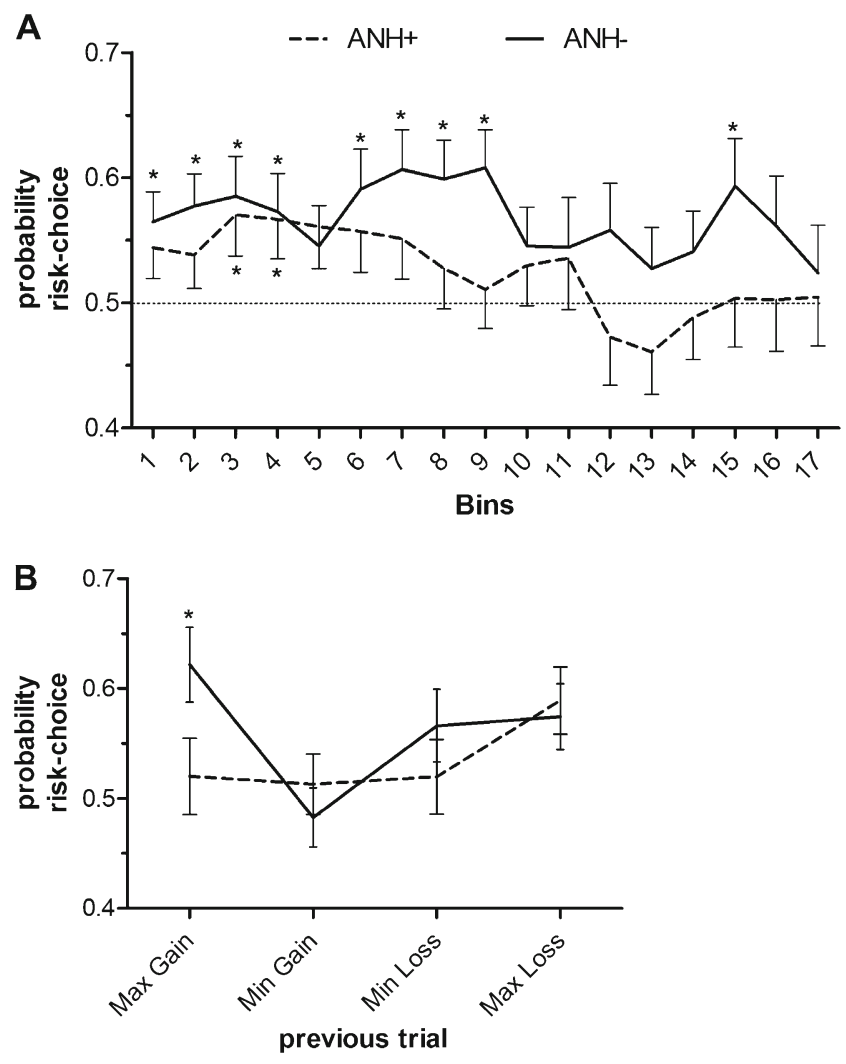

Fig. 3 a Evolution of the risk choices (choose 25 instead of 5) across the whole task. Each bin is composed of 40 trials (mean proportion of choosing 25 in that particular bin). The dotted horizontal line corresponds to chance level $(p=.5)$. The asterisks represent serial onesample $t$ tests in which the $25 / 5$ proportion was significant above chance level. Interestingly, during the first nine bins, the ANH- group showed a very consistent risk pattern (significantly above chance). This pattern was not observed in the $\mathrm{ANH}+$ group. b Lines (dashed, $\mathrm{ANH}+$; solid, ANH-) illustrating the probabilities of risk choices on the current trial $(n)$ when the previous trial $(n-1)$ had been (from left to right) a maximum gain, minimum gain, minimum loss, and maximum loss. Significantly, differences between the groups were observed after maximum gains. Error bars represent SEMs groups (ANH+ and $\mathrm{ANH}-)$. A significant effect of time bin was encountered $[F(1,41)=5.4, p<.05]$, showing that the proportions of risky choices were different across the task, but neither the group effect $[F(1,41)=1.4$, n.s. $]$ nor the Group $\times$ Time interaction $[F(1,41)=1.1$, n.s. $]$ was significant. Thus, although a significant tendency to incur risky choices appears in the ANH- results when compared to the expected chance level (see Fig. 3a), no clear differences were observed between groups across the task.

A sequential analysis was carried out in order to investigate how risk decisions were influenced by the outcome on the previous trial (Gehring \& Willoughby, 2002). The probability of taking risky decisions (i.e., choosing 25 rather than 5) in each trial ( $n$ ), depending on the outcome of the previous trial $(n-1)$, was studied using repeated measures ANOVAs [Risk (after maximum gain, minimum gain, minimum loss, or maximum loss $) \times$ Group]. The risk probability was computed as the number of times that participants selected the risky option (25) divided by the number of times that participants selected 25 or 5 with respect to the outcome on the previous trial. Using repeated measures ANOVAs, we entered the risk probability on each trial $(n)$ as a function of the outcome on the previous trial (n-1) (i.e., after maximum gain, minimum gain, minimum loss, or maximum loss) for each group. A main effect of risk was found $[F(3,123)=4.6, p<.01]$. As can be seen in Fig. 3b, the tendency to make risky decisions increased after losing the maximum amount on the previous trial (loss 25), but also - unlike the pattern reported in a prior study (Gehring \& Willoughby, 2002) - after gaining a large amount (25). Importantly, the significant interaction between group and risk $[F(3,123)=3.2, p<.05]$ showed that ANH- participants increased the amount of risk in their decisions after maximum monetary gains, in comparison with the $\mathrm{ANH}+$ group [pairwise $t$ test in this condition: $t(41)=-2.2, p<.05]$.

To provide more evidence regarding this behavioral pattern in the $\mathrm{ANH}+$ group, we carried out the same type of analysis, but evaluating risk preferences as a function of the outcomes on the two (n-2) and three (n-3) previous trials. Thus, instead of looking at the probability of choosing the risky option (25) immediately after a maximum gain (25) ( $n-$ 1 , in the previous analysis), we searched for those trials in which a maximum gain had been received during at least the last two (n-2) or three (n-3) consecutive trials before the current decision. Again, we observed a clear risk pattern in the ANH- group after two and three consecutive maximum gains as compared to the $\mathrm{ANH}+$ group. The behavioral pattern presented in Fig. 3b was reproduced and confirmed in the corresponding ANOVAs by the Risk (previous trial maximum gain, minimum gain, minimum loss, or maximum loss $) \times$ Group interaction for the $n-2[F(3,123)=3.3 p<.05]$ and $n-3[F(3,123)=3.2, p<.05]$ analyses. 
Finally, we investigated the degree to which the amount of risk observed in the decisions of both groups across the experiment (Fig. 3a) was related to the sensitivity of reward (SR) and punishment (SP) measures. We obtained a mean value of the probability to make risky decisions during the task for each participant (averaged across all 17 bins) (cf. Fig. 3a). A significant negative correlation was encountered between SP and the probability of increasing the risk $[r(43)=$ $-.397, p<.008]$. No significant correlation was observed with SR $[r(43)=.275$, n.s.]. Furthermore, when we divided the number of blocks into two parts (first vs. second), the correlation between risk and SP remained significant in both parts, but was more reliable in the second part of the experiment $[r(43)=-.32, p<.04$, vs. $r(43)=-.40, p<.006$, respectively $]$. Thus, this result suggests that the amount of risk in decisions was associated with the susceptibility to avoid negative outcomes (SP), with this effect being larger during the second half of the experiment.

In sum, the behavioral pattern suggests an overall increase of risky decisions in the ANH- participants during the task, in particular after receiving large monetary gains on the previous trials, when compared with the $\mathrm{ANH}+$ group. The amount of risk in these decisions was related to the trait measure of sensitivity to punishment.

FRN, medial-frontal theta activity, and the impact of monetary losses

After monetary losses, we observed a typical FRN that peaked between 260 and $310 \mathrm{~ms}$ for all participants (ANH+ and ANH-) (Fig. 4a). An ANOVA with Valence (gain, loss), Magnitude (averaged across maximum and minimum conditions), and Electrode Site (midline locations: $\mathrm{Fz}, \mathrm{Cz}, \mathrm{Pz}$ ) as factors revealed a main effect of valence $[F(1,41)=85.9, p<.001]$ that was larger at $\mathrm{Fz}$ [Electrode $\times$ Valence interaction: $F(2,82)=13.5, p<.001$; losses, $3.9 \pm 4.2 \mu \mathrm{V}$; gains, $8.8 \pm 5.3 \mu \mathrm{V}$; note that the absolute values are positive because the FRN is superimposed on a slow positive deflection]. To inspect the mean averages of the FRN for both groups, we computed the difference waveform (loss minus gain) at $\mathrm{Fz}$ (Fig. 4b). Although we observed a slight increase of the FRN for $\mathrm{ANH}+(-5.97 \pm 4.1 \mu \mathrm{V})$ when compared with ANH$(-4.4 \pm 2.8 \mu \mathrm{V})$, this difference did not reach statistical significance $[t(42)=-1.44$, n.s.; two-tailed comparison for the peak activity of the difference waveform, $280-310 \mathrm{~ms}]$.

Additionally, we inspected medial-frontal theta activity in response to the different monetary outcomes. We repeated the same statistical procedure using repeated measures ANOVA with Valence (gain, loss), Magnitude (maximum, minimum), and Electrode Site (3) as factors. We found greater activity in the theta range $(3-7 \mathrm{~Hz}$, time window 200-450 ms) for losses as compared with gains
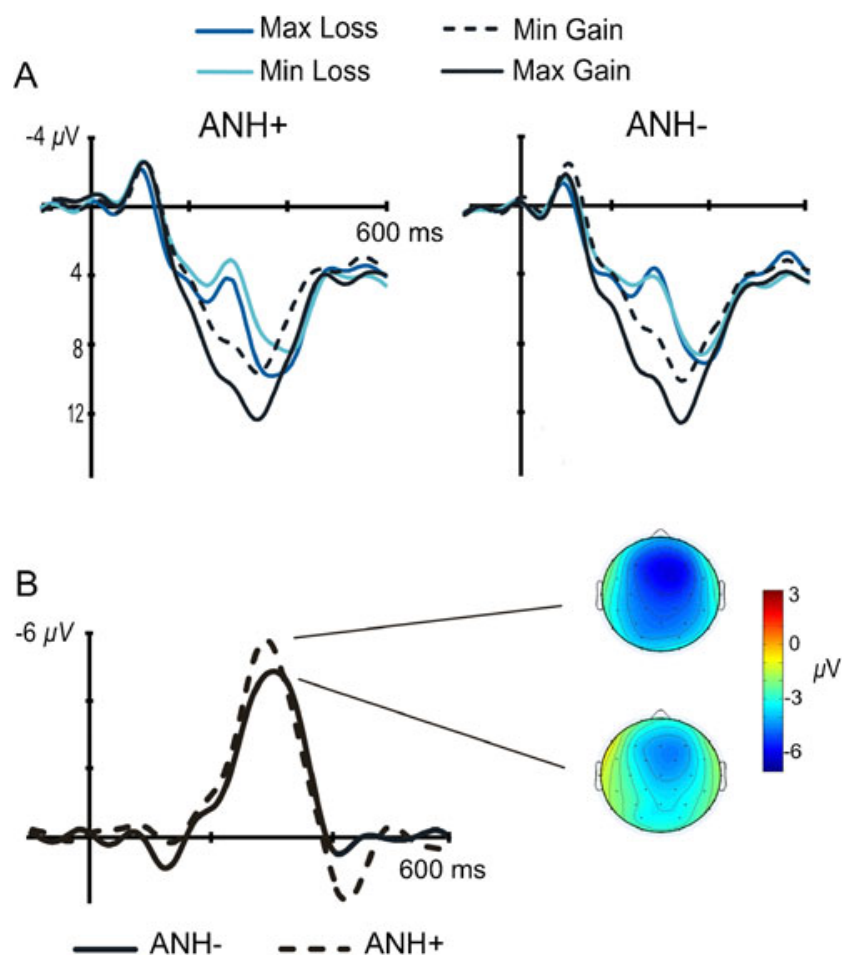

Fig. 4 a Grand average waveforms at $\mathrm{Fz}$ for both groups. Increased FRNs were observed in response to monetary losses (either 5-minimum loss-or 25-maximum loss). b Difference waveforms (loss minus gain trials) at frontal location Fz. Also depicted are the scalp distributions of the FRN component at the peak time window from the difference waveforms for the $\mathrm{ANH}+($ top $)$ and $\mathrm{ANH}-$ (bottom) groups

[valence effect: $F(1,41)=4.4, p<.05$ ] (Fig. 5a). This effect was greatest at the $\mathrm{Fz}$ electrode [Valence $\times$ Electrode: $F(2,82)=32.5, p<.0001$; see the frontocentral scalp distribution of the theta component in Fig. 5b]. In agreement with the FRN results, we did not find differences between the groups in response to monetary losses in the analysis confined to medial-frontal theta [Valence $x$ Group interaction: $F(1,41)<1$, n.s.]. However, the Valence $\times$ Magnitude $\times$ Group interaction $[F(1,41)=4.8$, $p<.05$ ] was significant, showing that the $\mathrm{ANH}+$ group had an increase in theta power activity after maximum gains. An ANOVA that was restricted to monetary gains (maximum, minimum) revealed a significant Gain $\times$ Group interaction $[F(1,41)=7.8, p<.005]$. As can be observed in Fig. 6a and b (difference between maximum gain and minimum gain), larger theta oscillatory activity was found among $\mathrm{ANH}+$ participants for maximum gains when compared with ANH- participants. Indeed, further pairwise comparisons showed that the magnitude effect for gains (maximum vs. minimum) was only significant in the ANH+ group $[t(20)=2.4, p<.05$; ANH-, $t(21)=$ $-1.5, p>.05]$. The same analysis carried out for maximum and minimum losses showed no significant interaction between magnitude and group $[F(1,41)=1$, n.s. $]$. 
A

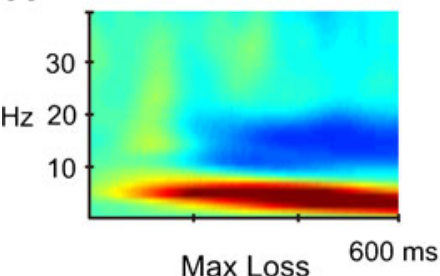

Max Loss
$600 \mathrm{~ms}$

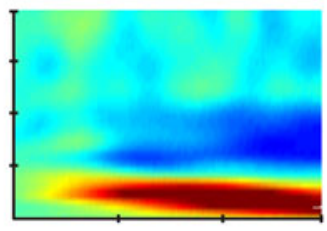

Min Loss

$\mathrm{ANH}+$

$\mathrm{ANH}-$

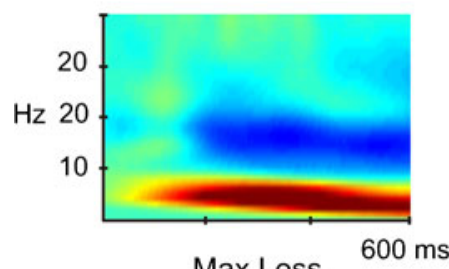

Max Loss

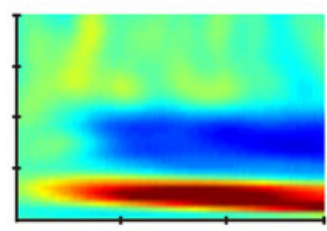

Min Loss

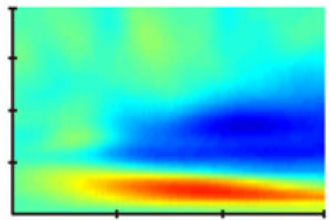

Min Gain

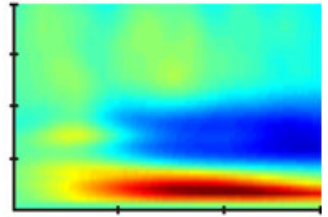

Max Gain

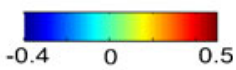

power increase

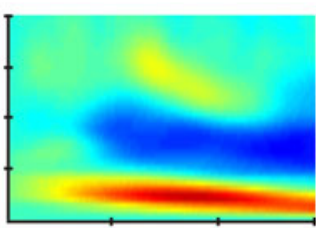

Max Gain

B

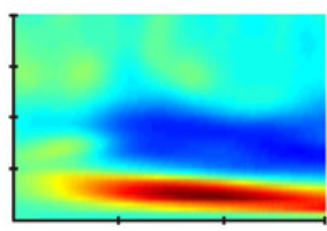

Min Gain
Max Gain - Max Loss

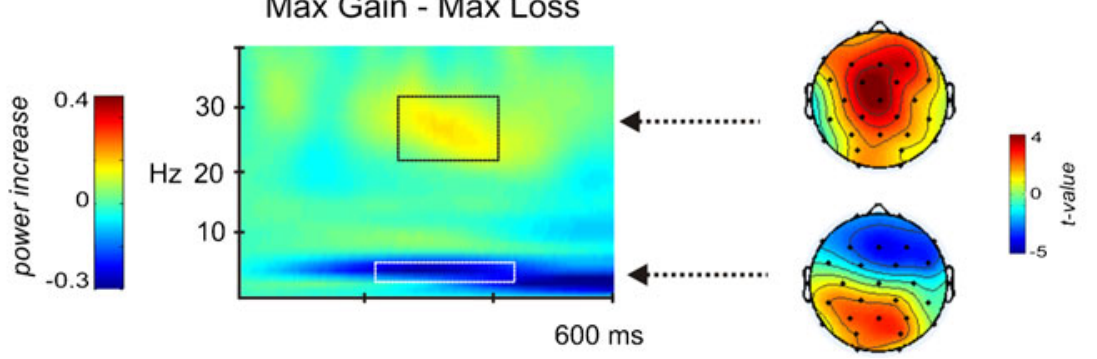

Fig. 5 a Change in power with respect to baseline (100 ms prior to feedback stimulus) relative to $\mathrm{Fz}$ for the different conditions in the $\mathrm{ANH}+$ and $\mathrm{ANH}-$ groups. b Differences between the maximum-gain and maximum-loss conditions for the entire sample, illustrating both the theta and beta-gamma oscillatory components. On the right are scalp distributions of the $t$ test (difference between maximum gain vs. maximum loss) for the theta (3-7 Hz, time window $200-450 \mathrm{~ms})$ and beta-gamma $(25-31 \mathrm{~Hz}, 260-350)$ components. Theta power is larger for loss than for gain trials, while beta-gamma oscillatory activity is larger for monetary gains than for losses
Beta-gamma activity and the impact of monetary gains

On the basis of previous findings (Cohen et al., 2007; Marco-Pallarés et al., 2008), we analyzed the power in beta-gamma oscillatory activity to study consummatory responses to monetary gains. In agreement with previous reports (Marco-Pallarés et al., 2008), beta-gamma power $(27-32 \mathrm{~Hz}, 270-310 \mathrm{~ms})$ was enhanced for monetary gains as compared to losses [main effect of valence: $F(1,41)=$ $7.7, p<.05]$. The effect of valence was greatest at the $\mathrm{Fz}$ electrode location [Valence $\times$ Electrode interaction: $F(2,82)$ $=6.7, p<.05]$ (see Fig. 5a and the topographical map of the beta component in Fig. 5b). No statistical differences in the Valence $\times$ Group interaction were encountered $[F(1,41)=$ 1.1, n.s.], nor for the Valence $\times$ Electrode $\times$ Group interaction $[F(2,82)=3.0, p<.08]$. Further inspection of this marginal interaction showed that this effect was due to a single outlier in the ANH- group that showed a power in the beta-gamma range $3 S D$ s above the mean value at the $\mathrm{Fz} / \mathrm{Cz}$ locations of the corresponding group. After removing this participant from the previous ANOVA, this analysis confirmed that no differences existed between groups in this oscillatory component [Valence $\times$ Electrode $\times$ Group: $F(2$, $80)<1$ ] associated with the processing of positive monetary gains.

Sequential analysis of medial-frontal theta modulations in maximum gains

Considering that after maximum-gain trials $(n-1, n-2$, or $n-$ 3 ) the difference between groups for the probability to make risky decisions was higher (Fig. 3b), we decided to further explore the modulation of theta activity in maximum-gain trials, which had differed clearly in the previous analysis between $\mathrm{ANH}+$ and $\mathrm{ANH}-$, depending on the previous outcomes (four levels: maximum gain, minimum gain, 


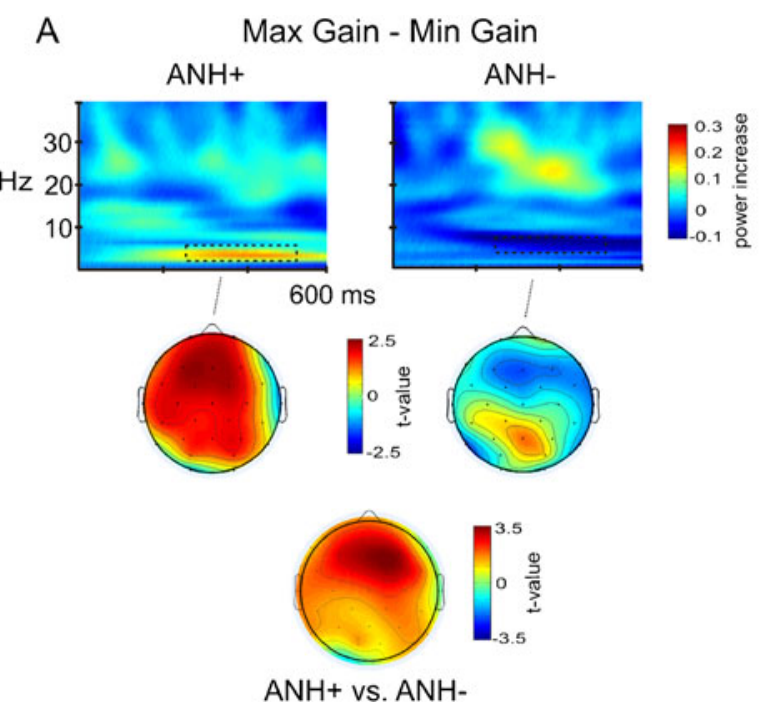

Fig. 6 a Power change with respect to baseline between gain (maximum vs. minimum) conditions at Fz. Observe the increase for the theta band $(3-7 \mathrm{~Hz})$ in the 250 to $450 \mathrm{~ms}$ time range for $\mathrm{ANH}+$ as compared with $\mathrm{ANH}-$ in response to maximum gains. In the bottom of the figure

minimum loss, or maximum loss). An additional ANOVA on the mean theta activity $(4-7 \mathrm{~Hz}$, time window 250 $500 \mathrm{~ms}$ ) of maximum-gain trials as a function of the outcome of the previous trial at midline electrode sites $(\mathrm{Fz}, \mathrm{Cz}$, $\mathrm{Pz}$ ) revealed a marginal interaction of Previous Trial $\times$ Group [linear trend: $F(1,41)=3.7, p<.06]$. As can be seen in Fig. 7a, after maximum-loss and minimum-loss trials, the theta activity was quite identical for both groups. In contrast, theta activity showed a tendency to behave differently between the groups after minimum-gain, and especially after maximum-gain, trials, with a tendency toward increased theta power in the $\mathrm{ANH}+$ group. This result somehow mirrors the behavioral effects presented before, in which the $\mathrm{ANH}+$ group did not show an increase in the amount of risk after maximum monetary gains (see Fig. 3b).

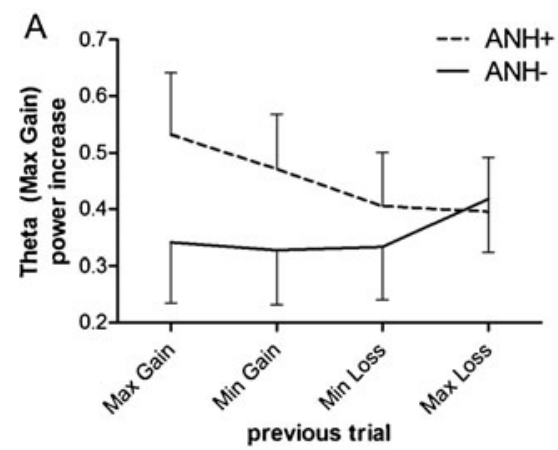

Fig. 7 a Representation of theta activity (4-7 Hz, time window 250 $500 \mathrm{~ms}$ ) in maximum-gain trials as a function of the previous trial, averaged across midline electrodes $(\mathrm{Fz}, \mathrm{Cz}$, and $\mathrm{Pz})$ for $\mathrm{ANH}+($ dotted line) and $\mathrm{ANH}-$ (solid line). Error bars represent SEMs. b Power change with respect to baseline in maximum-gain trials when the

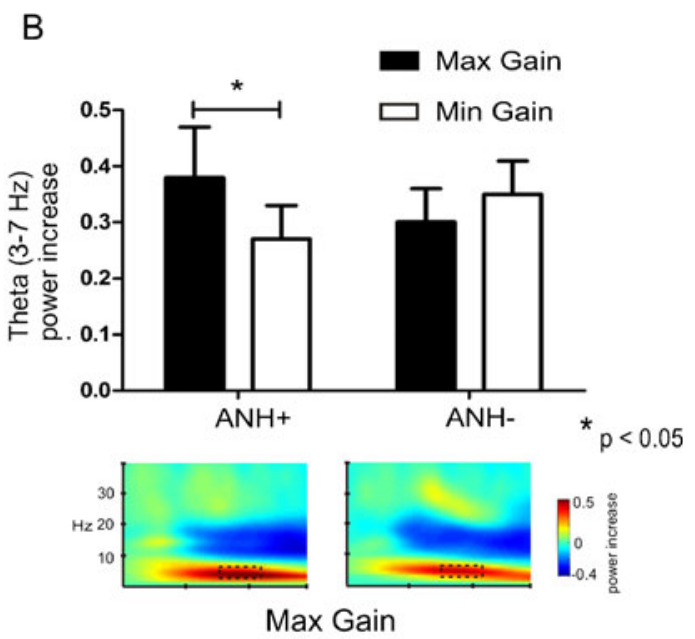

are depicted the scalp distributions of the medial-frontal theta activity $(t$ values). b Graphic representation of the differences between gain conditions regarding the theta band in both groups. Error bars represent SEMS

\section{Discussion}

The present study was designed to investigate individual neurophysiological differences related to reward processing in anhedonia. Using a standard gambling paradigm (Gehring \& Willoughby, 2002; Marco-Pallarés et al., 2008), we were able to evaluate consummatory responses to monetary gains and losses, as well as the motivational approach-behavior responses (risk patterns) in both groups. The present results will be discussed separately for both aspects, and in accordance with the two main conclusions that could be derived: (1) Individual differences in anhedonia, measured using Chapman's Physical Anhedonia Scale, were not related to dysfunctional deficits in consummatory aspects of reward processing, and (2) anhedonia was associated with differences in

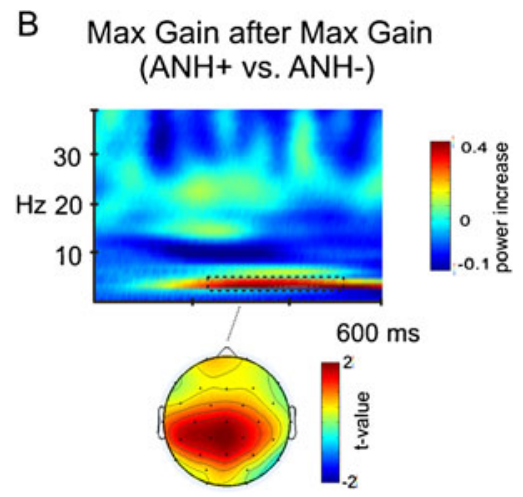

previous trial was also maximum gain (average of $\mathrm{Fz}, \mathrm{Cz}$, and $\mathrm{Pz}$ ), representing the difference between groups ( $\mathrm{ANH}+$ minus $\mathrm{ANH}-$ ). Also depicted is the scalp distribution of the medial-frontal theta activity ( $t$ values) 
motivational approach behavior, which were reflected in a higher sensitivity to punishment, an increase in cognitive control when large amounts of unexpected rewards were obtained, and a decrease in risky decisions immediately after receiving large monetary rewards.

Consummatory responses to monetary rewards in anhedonia

One of the main results of this study was that consummatory responses in anhedonics did not show any noticeable deficit in reward processing induced by monetary gains or losses. Indeed, no differences were observed in the medial-frontal FRN component (Gehring \& Willoughby, 2002; Holroyd \& Coles, 2002) or in theta oscillatory activity associated with monetary losses (Cohen et al., 2007; Marco-Pallarés et al., 2008; Marco-Pallarés et al., 2009) (see Fig. 4). The FRN was not reduced in the ANH+ group, which differed from previous reports in which depressed patients showed reduced FRNs (Foti \& Hajcak, 2009) or increased amplitude (Santesso et al., 2008; Tucker, Luu, Frishkoff, Quiring, \& Poulsen, 2003). Notice, however, that our sample was composed of healthy individuals, and although anhedonia is a core symptom of depression, it is difficult to compare the present results with the ones obtained in clinical studies with depressive patients, as other important factors affecting depression could be responsible for the difference in the FRN amplitudes. In any case, the present results are clear, regarding the FRN and medial theta activity suggesting normal processing of negative outcomes in $\mathrm{ANH}+$ participants.

The same pattern was observed for the delivery of positive feedback associated with monetary gains: No differences were found between anhedonic and nonanhedonic participants in the beta-gamma oscillatory component. Previous research had suggested that beta-gamma activity is a possible neural marker of reward associated with monetary gains (Marco-Pallarés et al., 2008; Marco-Pallarés et al., 2009) and positive feedback (Cohen et al., 2007; Cunillera et al., 2012; Haji Hosseini et al., 2012). Animal studies have observed increases of beta activity in the striatum after reward delivery (Courtemanche, Fuji, \& Graybiel, 2003). In humans, consummatory behavior (drinking) was associated with an increase in cortical EEG beta power (Hallschmid et al., 2002). Due to the large network involved in the processing of reward and positive affect (orbitofrontal and mPFC and ventral striatum), as has been shown in fMRI studies (Knutson, Fong, Bennett, Adams, \& Hommer, 2003; O'Doherty, Kringelbach, Rolls, Hornak, \& Andrews, 2001; Yacubian et al., 2006), our lab has proposed that beta activity orchestrates reward processing through such aforementioned fronto-striatal circuits (Camara, Rodriguez-Fornells, \& Münte, 2010; Marco-Pallarés et al., 2008). As a sign of consummatory behavior, beta-gamma activity did not show significant differences between the $\mathrm{ANH}+$ and $\mathrm{ANH}-$ groups, corroborating previous findings of intact hedonic responses in anhedonic and depressive patients (Berenbaum et al., 1987; Berlin et al., 1998; Germans \& Kring, 2000). For example, using the sweet-taste test, no differences were found in a group of depressive patients regarding the hedonic responses elicited by natural reinforcers supporting an unimpaired feeling of pleasure (Berlin et al., 1998).

Anticipatory deficits in anhedonia are related to increased sensitivity to punishment

Albeit no differences were observed in the FRN or the betagamma component due to monetary losses and gains, we observed an unpredicted increase in medial-frontal theta oscillatory activity in the $\mathrm{ANH}+$ group after maximumgain trials (see Fig. 6). Moreover, in a further exploratory sequential analysis, we showed that this increase in theta activity in the ANH+ group in maximum-gain trials tended to be larger when trials were also preceded by a maximumgain trial (see Fig. 7). It is important to bear in mind that increases in theta oscillatory power are normally associated with negative feedback conditions, erroneous processing, or violation of current expectations. This medial-frontal theta activity has also been observed in relation to the increase in cognitive control and conflict detection (Botvinick, Braver, Barch, Carter, \& Cohen, 2001; Ridderinkhof et al., 2004), as well as to the computation of expectancy deviation predicting the value of actions (Matsumoto, Matsumoto, Abe, \& Tanaka, 2007; Oliveira, McDonald, \& Goodman, 2007; Walton, Devlin, \& Rushworth, 2004). In this sense, it has been proposed that medial frontal theta activity represents the broad coordination of several brain regions implicated in action monitoring and control processes (Cavanagh et al., 2010). Accordingly, theta power increases seem to be relevant for task switching (Cunillera et al., 2012), for improving learning (van de Vijver et al., 2011), and for future behavioral adjustments (Cavanagh, Cohen, \& Allen, 2009; Cavanagh et al., 2010; Womelsdorf et al., 2010).

Considering previous studies in which a tendency was proposed for depressive patients to create negative expectations about future events (Lloyd \& Lishman, 1975; Nelson $\&$ Craighead, 1977), the present results might show that anhedonia could play a significant role in the maintenance and buildup of these negative predictions. Thus, the unexpected enhancement of theta activity in $\mathrm{ANH}+$ participants could be interpreted as a violation of negative expectations created across the task. When an unexpected reward is delivered, it might trigger an internal conflict between prior expectations, which are naturally influenced by reward and motivational representations, and the present outcome. Consistent with our interpretation, it has been observed that small reward probabilities (Cohen et al., 2007) and highrisk situations (Christie \& Tata, 2009) elicit greater theta- 
band power following win trials. Besides, Tzur and Berger (2009) proposed that theta activity might reflect a violation of the created expectation - that is, a conflict arising between the expected rule and the information delivered. In this sense, the ANH+ group after receiving positive feedback might be expecting a negative one, but the delivery of new positive feedback might violate this expectation and induce the increase in theta activity. This interpretation is indeed in agreement with the explanation behind the FRN, in which larger theta oscillatory activity is predicted for worse-than-expected outcomes. As the $\mathrm{ANH}+$ group might be biased toward negative events, and in accord with the ideas considered previously about the negative expectation bias in depressive patients, the appearance of largemagnitude gains might elicit an increase in cognitive control and the corresponding increase in theta activity (unexpected gains). Thus, these results speak in favor of an interpretation of the cognitive mechanisms associated with anhedonia as being related to a problem in sustaining positive expectations about the outcomes of their actions (Heller et al., 2009; Treadway \& Zald, 2011). In the same vein, it has been demonstrated that unmedicated depressed individuals display an impaired tendency to modulate behavior as a function of previous rewards, indicating a lack of capacity to integrate a reinforcement history over time (Pizzagalli, Losifescu, Hallett, Ratner, \& Fava, 2008).

More behavioral evidence of this negative bias might be the significantly reduced engagement in risky choices in the $\mathrm{ANH}+$ group (i.e., choosing the larger magnitude, 25 instead of 5, in the gambling task; see Fig. 3a), when compared to the expected chance level. Indeed, the amount of risky decisionmaking in the present task was inversely associated with the sensitivity to punishment (SP). Psychometrically, the ANH+ group was also characterized by an amplified sensitivity to possible punishments (Fig. 2). This trait might be conditioning at a behavioral level their marked tendency to choose nonrisky bets across the task. On the one hand, this behavioral pattern restricts the possibility of obtaining larger gains, but on the other hand, it is coherent with their so-called negative bias about future rewards (commented on previously), and their impediment to sustaining positive expectations about the results of their own behavior. Similarly, depressive individuals presume that negative outcomes are more likely for their actions in more uncertain situations (Beck, 1979; Lloyd \& Lishman, 1975; Nelson \& Craighead, 1977). In conformity with classic theories of depression (Alloy \& Abramson, 1979), anhedonics might have less propensity to perceive reality in an optimistic fashion, and consequently might avoid occasions that could potentially be highly positive and pleasurable. In light of this concern, and in agreement with the importance of anhedonia in risk taking, a recent study demonstrated that schizophrenic patients with high levels of anhedonia are less prone to explore uncertain environments, probably due to their prior negative expectations and reduced sensitivity to coding opportunities that could be better than expected (Strauss et al., 2011).

In our study, the sequential analysis showed that the outcome values of previous trials interfered with the risk-taking behavior exhibited by our participants, differentially for both groups. The probability to make risky choices increased after maximum-loss trials for both groups, and as expected, considering previous studies (Gehring \& Willoughby, 2002). Nevertheless, after maximum gains, different patterns of behavior were observed, with the $\mathrm{ANH}+$ group showing fewer tendencies to invest in risky choices (Fig. 3b) when compared to the ANH- group. This is probably due to reduced capacity to sustain positive reinforcements across time, which affects their confidence about the possibility of being rewarded in future trials. These results also fit nicely with the increased susceptibility to punishment as well as the increased cognitive control reflected in theta power after receiving large monetary gains.

Finally, it is important to mention a possible limitation of the present study in relation to how the groups were created, based on Chapman's Physical Anhedonia Scale values. Two extreme groups were formed, a highly anhedonic group $(\mathrm{ANH}+, \mathrm{PAS}$ value above 24$)$ and a highly hedonic group $(\mathrm{ANH}-$, PAS $<4)$. Thus the results reported here need to be considered with caution, and bearing in mind that the differences observed could be driven by the highly hedonic group. For example, the risk pattern depicted in Fig. 3b, in which the amount of risk is increased in the nonanhedonic group after maximum gains, could be due to the extreme sensitivity of this group to receive large monetary rewards, instead of to the lack of response of the anhedonic group to this type of rewards. It is interesting to note that the hedonic group in the present study differed from other control groups created in previous investigations that have evaluated emotional processing in anhedonic participants. In these studies, less extreme scores were used to create the nonanhedonic group (e.g., in Fitzgibbons \& Simons, 1992, the control was created based on central PAS scores; see also Berenbaum et al., 1987; Germans \& Kring, 2000; and Rey et al., 2010, who also used lower values for the control group, $\pm 0.25 S D$ ). Further research will be needed in which a control group could be used to explore the present findings and compare them with those for highly hedonic and nonanhedonic participants. A further limitation of this study could be related to a decrease of motivation in the anhedonic group as compared to the nonanhedonic group, which could be responsible for the sequential effects encountered. Although this explanation is in contradiction with the present findings of equal electrophysiological responses after positive and negative feedback presentation, they could still explain the lack of increase in risk after receiving very positive feedback. 


\section{Conclusions}

To our knowledge, this is the first study to address trait anhedonia in healthy individuals by combining psychometric, behavioral, and neurophysiological data. The results reported here show that a thorough understanding of anhedonia, traditionally seen as a unified concept, and its psychopathological implications requires a separation between its consummatory and anticipatory components (see also Treadway \& Zald, 2011). Anhedonia seems to be characterized by a tendency to create negative expectations toward upcoming reward events, which might be reflected in an elevated sensitivity to punishment and in the avoidance of risky decisions. Importantly, no electrophysiological differences were observed due to anhedonia in reward processing of positive or negative outcomes (in the present case, monetary gains and losses). This result speaks in favor of preserved consummatory reward processing. However, anhedonic participants were psychometrically more sensitive to possible punishments and clearly showed deficits in the correct integration of response outcomes in their actionsfor example, not showing strategic risk modulations in their decisions when compared to the nonanhedonic group. Besides, after receiving a large monetary gain, the anhedonic group showed a drastic increase in medial-frontal theta activity, classically associated with negative events, conflict detection, and an increase in cognitive control. The singular way that anhedonics processed positive reinforcements might have been affected by default negative expectations that characterize their cognitive style. Thus, the occurrence of events that were better than expected might have increased the degree of cognitive conflict in consummatory responses of pleasure. In sum, participants with elevated scores in the Physical Anhedonia Scale might have an intact hedonic capacity but an impairment in anticipating future positive outcome rewards that might make their engagement in pleasurable activities less likely.

Author note This research was supported by a grant from the Ramon y Cajal Program, awarded to J.M.P., and by grants from the Spanish Government (MICINN; Grants PSI2008-03901, to A.R.F., and PSI2009-09101, to J.M.P.) and the Catalan Government (Generalitat de Catalunya, 2009 SGR 93).

\section{References}

Alloy, L. B., \& Abramson, L. Y. (1979). Judgment of contingency in depressed and nondepressed students: Sadder but wiser? Journal of Experimental Psychology. General, 108, 441-485. doi:10.1037/0096-3445.108.4.441

Barbano, M. F., \& Cador, M. (2007). Opioids for hedonic experience and dopamine to get ready for it. Psychopharmacology, 191, 497506.
Barch, D. M., \& Dowd, E. C. (2010). Goal representations and motivational drive in schizophrenia: The role of prefrontal-striatal interactions. Schizophrenia Bulletin, 36, 919-934.

Beck, A. (1979). Cognitive theory of depression. New York: Wiley.

Berenbaum, H., Snowhite, R., \& Oltmanns, T. F. (1987). Anhedonia and emotional responses to affect evoking stimuli. Psychological Medicine, 17, 677-684.

Berlin, I., Givry-Steiner, L., Lecrubier, Y., \& Puech, A. J. (1998). Measures of anhedonia and hedonic responses to sucrose in depressive and schizophrenic patients in comparison with healthy subjects. European Psychiatry, 13, 303-309.

Berridge, K. C. (2004). Motivation concepts in behavioral neuroscience. Physiology and Behavior, 81, 179-209.

Berridge, K. C., \& Kringelbach, M. L. (2008). Affective neuroscience of pleasure: Reward in humans and animals. Psychopharmacology, 199, 457-480.

Berridge, K. C., \& Robinson, T. E. (1998). What is the role of dopamine in reward: Hedonic impact, reward leaning, or incentive salience? Brain Research Review, 28, 309-369.

Berrios, G. E., \& Olivares, J. M. (1995). The anhedonias: A conceptual history. History of Psychiatry, 6, 453-470.

Blanchard, J. J., Horan, W. P., \& Brown, S. A. (2001). Diagnostic differences in social anhedonia: A longitudinal study of schizophrenia and major depressive disorder. Journal of Abnormal Psychology, 110, 363-371.

Bogdan, R., \& Pizzagalli, D. A. (2009). The heritability of hedonic capacity and perceived stress: A twin study evaluation of candidate depressive phenotypes. Psychological Medicine, 39, 211-218.

Botvinick, M. M., Braver, T. S., Barch, D. M., Carter, C. S., \& Cohen, J. D. (2001). Conflict monitoring and cognitive control. Psychological Review, 108, 624-652. doi:10.1037/0033-295X.108.3.624

Botvinick, M. M., Cohen, J. D., \& Carter, C. S. (2004). Conflict monitoring and anterior cingulate cortex: An update. Trends in Cognitive Sciences, 8, 539-546. doi:10.1016/j.tics.2004.10.003

Burgdorf, J., \& Pankseep, J. (2006). The neurobiology of positive emotions. Neuroscience and Biobehavioral Reviews, 30, 173-187.

Camara, E., Krämer, U. M., Cunillera, T., Marco-Pallarés, J., Cucurell, D., Nager, W., \& Münte, T. F. (2010a). The effects of COMT (Val108/158Met) and DRD4 (SNP -521) dopamine genotypes on brain activations related to valence and magnitude of rewards. Cerebral Cortex, 20, 1985-1996. doi:10.1093/cercor/bhp263

Camara, E., Rodriguez-Fornells, A., \& Münte, T. F. (2010b). Microstructural brain differences predict functional hemodynamic responses in a reward processing task. Journal of Neuroscience, 30, 11398-11402. doi:10.1523/JNEUROSCI.0111-10.2010

Carter, C. S., \& van Veen, V. (2007). Anterior cingulate cortex and conflict detection: An update of theory and data. Cognitive, Affective, \& Behavioral Neuroscience, 7, 367-379. doi:10.3758/ CABN.7.4.367

Carver, C. S., \& White, T. L. (1994). Behavioral inhibition, behavioral activation, and affective responses to impending reward and punishment: The BIS/BAS scales. Journal of Personality and Social Psychology, 67, 319-333.

Cavanagh, J. F., Cohen, M. X., \& Allen, J. J. (2009). Prelude to and resolution of an error: EEG phase synchrony reveals cognitive control dynamics during action monitoring. Journal of Neuroscience, 29, 98-105.

Cavanagh, J. F., Frank, M. J., Klein, T. J., \& Allen, J. J. B. (2010). Frontal theta links prediction errors to behavioral adaptation in reinforcement learning. NeuroImage, 49, 3198-3209.

Chapman, L. J., Chapman, J. P., \& Raulin, M. L. (1976). Scales for physical and social anhedonia. Journal of Abnormal Psychology, $85,374-382$.

Chentsova-Dutton, Y., \& Hanley, K. (2010). The effects of anhedonia and depression on hedonic responses. Psychiatry Research, 179, 176-180. 
Christie, G. J., \& Tata, M. S. (2009). Right frontal cortex generates reward-related theta-band oscillatory activity. NeuroImage, 48, 415-422.

Cohen, M. X., Elger, C. E., \& Ranganath, C. (2007). Reward expectation modulates feedback-related negativity and EEG spectra. NeuroImage, 35, 968-978.

Courtemanche, R., Fuji, N., \& Graybiel, A. M. (2003). Synchronous, focally modulated beta-band oscillations characterize local field potential activity in the striatum of awake behaving monkeys. Journal of Neuroscience, 23, 11741-11752.

Cunillera, T., Fuentemilla, L., Periañez, J., Marco-Pallarès, J., Krämer, U. M., Càmara, E., \& Rodríguez-Fornells, A. (2012). Brain oscillatory activity associated with task switching and feedback processing. Cognitive, Affective, \& Behavioral Neuroscience, 12, 16-33. doi:10.3758/s13415-011-0075-5

Fitzgibbons, L., \& Simons, R. F. (1992). Affective response to colorslide stimuli in subjects with physical anhedonia: A three-systems analysis. Psychophysiology, 29, 613-620.

Foti, D., \& Hajcak, G. (2009). Depression and reduced sensitivity to non-rewards versus rewards: Evidence from event-related potentials. Biological Psychology, 81, 1-8.

Foussias, G., \& Remington, G. (2008). Negative symptoms in schizophrenia: Avolition and Occam's razor. Schizophrenia Bulletin, 36 , 359-369.

Gard, D. E., Kring, A. M., Gard, M. G., Horan, W. P., \& Green, M. F. (2007). Anhedonia in schizophrenia: Distinctions between anticipatory and consummatory pleasure. Schizophrenia Research, 93, 253-260.

Gehring, W. J., \& Willoughby, A. R. (2002). The medial frontal cortex and the rapid processing of monetary gains and losses. Science, $295,2279-2282$

Germans, M. K., \& Kring, A. M. (2000). Hedonic deficit in anhedonia: Support for the role of approach motivation. Personality and Individual Differences, 28, 659-672.

Gottesman, I. I., \& Gould, T. D. (2003). The endophenotype concept in psychiatry: Etymology and strategic intentions. The American Journal of Psychiatry, 160, 636-645.

Gray, J. A. (1981). A critique of Eysenck's theory of personality. In H. Eysenck (Ed.), A model for personality (pp. 246-276). Berlin, Germany: Springer.

Haji Hosseini, A., Rodríguez-Fornells, A., \& Marco-Pallarés, J. (2012). The role of beta-gamma oscillatory activity in reward processing. NeuroImage, 60, 1678-1685.

Hallschmid, M., Molle, M., Fisher, S., \& Born, J. (2002). EEG synchronization upon reward in man. Clinical Neurophysiology, 113, 1065 .

Harvey, P.-O., Armony, J., Malla, A., \& Lepage, M. (2010). Functional neural substrates of self-reported physical anhedonia in non-clinical individuals and in patients with schizophrenia. Journal of Psychiatric Research, 44, 707-716. doi:10.1016/j.jpsychires.2009.12.008

Harvey, P.-O., Pruessner, J., Czechowska, Y., \& Lepage, M. (2007). Individual differences in trait anhedonia: A structural and functional magnetic resonance imaging study in non-clinical subjects. Molecular Psychiatry, 12(703), 767-703. 775.

Hasler, G., Drevets, W. C., Manji, H. K., \& Charney, D. S. (2004). Discovering endophenotypes for major depression. Neuropsychopharmacology, 29, 1765-1781.

Heller, A. S., Johnstone, T., Shackman, A. J., Light, S. N., Peterson, M. J., Kolden, G. G., \& Davidson, R. J. (2009). Reduced capacity to sustain positive emotion in major depression reflects diminished maintenance of fronto-striatal brain activation. Proceedings of the National Academy of Sciences, 106, 22445-22450. doi:10.1073/ pnas.0910651106

Herbener, E. S., \& Harrow, M. (2002). The course of anhedonia during 10 years of schizophrenic illness. Journal of Abnormal Psychology, $111,237-248$.
Herbener, E. S., Harrow, M., \& Hill, S. K. (2005). Change in relationship between anhedonia and functional deficits over 20 -year period in individuals with schizophrenia. Schizophrenia Research, 75, 97-105.

Holroyd, C. B., \& Coles, M. G. H. (2002). The neural basis of human error processing: Reinforcement learning, dopamine, and the error-related negativity. Psychological Review, 109, 679-709. doi:10.1037/0033-295X.109.4.679

Kahneman, D., \& Tversky, A. (1979). Prospect theory: An analysis of decision under risk. Econometrica, 47, 263-292.

Keedwell, P. A., Andrew, C., Williams, S. C., Brammer, M. J., \& Phillips, M. L. (2005). The neural correlates of anhedonia in major depressive disorder. Biological Psychiatry, 58, 843-853.

Knutson, B., Fong, G. W., Bennett, S. M., Adams, C. M., \& Hommer, D. (2003). A region of mesial prefrontal cortex tracks monetarily rewarding outcomes: Characterization with rapid event-related fMRI. NeuroImage, 18, 263-272.

Kring, A. M., \& Moran, E. K. (2008). Emotional response deficits in schizophrenia: insights from affective science. Schizophrenia Bulletin, 34, 819-834.

Lewinsohn, P. M., Youngren, M. A., \& Grosscup, S. J. (1979). Reinforcement and depression. In A. Depue (Ed.), The psychobiology of depressive disorders: Implications for the effects of stress. New York: Academic Press.

Lloyd, G. G., \& Lishman, W. A. (1975). Effect of depression on the speed of recall of pleasant and unpleasant experiences. Psychological Medicine, 5, 173-180.

Loas, G. (1996). Vulnerability to depression: A model centered on anhedonia. Journal of Affective Disorders, 41, 39-53.

Marco-Pallarés, J., Cucurell, D., Cunillera, T., García, R., AndrésPueyo, A., Münte, T. F., \& Rodríguez-Fornells, A. (2008). Human oscillatory activity associated to reward processing in a gambling task. Neuropsychologia, 46, 241-248. doi:10.1016/ j.neuropsychologia.2007.07.016

Marco-Pallarés, J., Cucurell, D., Cunillera, T., Krämer, U. M., Càmara, E., Nager, W., \& Rodríguez-Fornells, A. (2009). Genetic variability in the dopamine system (dopamine receptor D4, catechol-Omethyltransferase) modulates neurophysiological responses to gains and losses. Biological Psychiatry, 66, 154-161. doi:10.1016/j.biopsych.2009.01.006

Matsumoto, M., Matsumoto, K., Abe, H., \& Tanaka, K. (2007). Medial prefrontal cell activity signaling prediction errors of action values. Nature Neuroscience, 10, 647-656.

Meehl, P. (1975). Hedonic capacity: Some conjectures. Bulletin of the Menninger Clinic, 39, 297-307.

Naranjo, C. A., Tremblay, L. K., \& Busto, U. E. (2001). The role of brain reward system in depression. Progress in Neuropsychopharmacology and Biological Psychiatry, 25, 781-823.

Nelson, R. E., \& Craighead, W. E. (1977). Selective recall of positive and negative feedback, self-control behaviors, and depression. Journal of Abnormal Psychology, 86, 379-388.

Nestler, E. J., \& Carlezon, W. A. (2006). The mesolimbic dopamine reward circuit in depression. Biological Psychiatry, 59, 381-391.

Nieuwenhuis, S., Holroyd, C. B., Mol, N., \& Coles, M. G. H. (2004). Reinforcement-related brain potentials from medial frontal cortex: Origins and functional significance. Neuroscience and Biobehavioral Reviews, 28, 441-448.

O’Doherty, J., Kringelbach, M. L., Rolls, T., Hornak, J., \& Andrews, C. (2001). Abstract reward and punishment representations in the human orbitofrontal cortex. Nature Neuroscience, 4, 95-102.

Oliveira, F. T., McDonald, J. J., \& Goodman, D. (2007). Performance monitoring in the anterior cingulate is not all error related: expectancy deviation and the representation of action-outcome associations. Journal of Cognitive Neuroscience, 19, 1994-2004.

Pizzagalli, D. A., Holmes, A. J., Dillon, D. G., Goetz, E. L., Birk, J. L., Bogdan, R., \& Fava, M. (2009). Reduced caudate and nucleus accumbens response to rewards in unmedicated individuals with 
major depressive disorder. The American Journal of Psychiatry, 166, 702-710. doi:10.1176/appi.ajp.2008.08081201

Pizzagalli, D. A., Jahn, A. L., \& O'Shea, J. P. (2005). Toward an objective characterization of an anhedonic phenotype: A signaldetection approach. Biological Psychiatry, 57, 319-327.

Pizzagalli, D. A., Losifescu, D., Hallett, L. A., Ratner, K. G., \& Fava, M. (2008). Reduced hedonic capacity in major depressive disorder: Evidence from a probabilistic reward task. Journal of Psychiatric Research, 43, 76-87.

Rey, G., Knoblauch, K., Prévost, M., Komano, E., Jouvent, R., \& Dubal, S. (2010). Visual modulation of pleasure in subjects with physical and social anhedonia. Psychiatry Research, 176, 155156

Richardson, D. K., Reynolds, S. M., Cooper, S. J., \& Berridge, K. C. (2005). Endogenous opioids are necessary for benzodiazepine palatability enhancement: Naltrexone blocks diazepam-induced increase of sucrose-"liking. Pharmacology Biochemistry and Behavior, 81, 657-663.

Ridderinkhof, K. R., Ullsperger, M., Crone, E. A., \& Nieuwenhuis, S. (2004). The role of the medial frontal cortex in cognitive control. Science, 306, 443-447. doi:10.1126/science.1100301

Salamone, J. D., Correa, M., Farrar, A., \& Mingote, S. M. (2007). Effort-related functions of nucleus accumbens dopamine and associated forebrain circuits. Psychopharmacology, 191, 461-482.

Santesso, D. L., Steele, K. T., Bogdan, R., Holmes, A. J., Deveney, C. M., Meites, T. M., \& Pizzagalli, D. A. (2008). Enhanced negative feedback responses in remitted depression. NeuroReport, 19, 1045-1048. doi:10.1097/WNR.0b013e3283036e73

Shankman, S. A., Nelson, B. D., Harrow, M., \& Faull, R. (2010). Does physical anhedonia play a role in depression? A 20-year longitudinal study. Journal of Affective Disorders, 120, 170-176. doi:10.1016/j.jad.2009.05.002

Sherdell, L., Waugh, C. E., \& Gotlib, I. H. (2012). Anticipatory pleasure predicts motivation for reward in major depression. Journal of Abnormal Psychology, 121, 51-60. doi:10.1037/a0024945

Smith, K. S., \& Berridge, K. C. (2007). Opioid limbic circuit for reward: Interaction between hedonic hotspots of nucleus accumbens and ventral pallidum. Journal of Neuroscience, 27, 15941605 .
Steele, J. D., Kumar, P., \& Ebmeier, K. P. (2007). Blunted response to feedback information in depressive illness. Brain, 130, 23672374 .

Strauss, G. P., Frank, M. J., Waltz, J. A., Kazanova, Z., Herbener, E. S., \& Gold, J. M. (2011). Deficits in positive reinforcement learning and uncertainty-driven exploration are associated with distinct aspects of negative symptoms in schizophrenia. Biological Psychiatry, 69, 424-431.

Torrubia, R., Ávila, C., Molto, J., \& Caseras, X. (2001). The Sensitivity to Punishment and Sensitivity to Reward Questionnaire (SPSRQ) as a measure of Gray's anxiety and impulsivity dimensions. Personality and Individual Differences, 31, 837-862.

Treadway, M. T., \& Zald, D. H. (2011). Reconsidering anhedonia in depression: Lessons from translational neuroscience. Neuroscience and Biobehavioral Reviews, 35, 537-555. doi:10.1016/ j.neubiorev.2010.06.006

Trujillo, L. T., \& Allen, J. J. (2007). Theta EEG dynamics of the errorrelated negativity. Clinical Neurophysiology, 118, 645-668.

Tucker, D. M., Luu, P., Frishkoff, G., Quiring, J., \& Poulsen, C. (2003). Frontolimbic response to negative feedback in clinical depression. Journal of Abnormal Psychology, 112, 667-678.

Tzur, G., \& Berger, A. (2009). Fast and slow brain rhythms in rule/ expectation violation tasks: Focusing on evaluation processes by excluding motor action. Behavioural Brain Research, 198, 420-428.

van de Vijver, I., Ridderinkhof, K. R., \& Cohen, M. X. (2011). Frontal oscillatory dynamics predict feedback learning and action adjustment. Journal of Cognitive Neuroscience, 23, 4106-4121. doi:10.1162/ jocn a 00110

Walton, M. E., Devlin, J. T., \& Rushworth, M. F. (2004). Interactions between decision making and performance monitoring within prefrontal cortex. Nature Neuroscience, 7, 1259-1265.

Womelsdorf, T., Johnston, K., Vinck, M., \& Everling, S. (2010). Thetaactivity in anterior cingulate cortex predicts task rules and their adjustments following errors. Proceedings of the National Academy of Sciences, 107, 5248-5253.

Yacubian, J., Glascher, J., Schroeder, K., Sommer, T., Braus, D. F., \& Buchel, C. (2006). Dissociable systems for gain- and loss-related value predictions and errors of prediction in the human brain. Journal of Neuroscience, 26, 9530-9537. 